\title{
Exogenous Melatonin Ameliorates Pontine Histoarchitecture and Associated Oxidative Damage in Sodium Fluoride Induced Toxicity
}

Sulaimon Fatimo Ajoke $M S c^{1}$, Okesina Akeem Ayodeji $P h D^{2}$, Imam Abubakar Leken $M S c^{3}$, Usman Ruqayyah Yetunde $M S c^{4}$, Ibrahim-Abdulkareem Rukayat Abiodun $M S c^{5}$, Imam Aminu $P \boldsymbol{P D}^{6}$, Adana Misturah Yetunde $P h D^{7}$, Shehu Monsur $M S c^{8}$, Abioye Adesola 'Idowu Raheem $P h D^{9}$, Ayuba Aishat Iyabo $M S c^{10}$, Ajao Moyosore Salihu $P h D^{11}$ 1,3,4,5,6,7,8,9,10,11 Department of Anatomy, Faculty of Basic Medical Sciences, University of Ilorin, ${ }^{2}$ Department of Human Anatomy, Faculty of Biomedical Sciences, Kampala International University

Date of submission: $30^{\text {th }}$ May 2020

Date of acceptance: $16^{\text {th }}$ July 2020

Date of publication: $12^{\text {th }}$ August 2020

\section{Abstract}

Background: Sodium fluoride $(\mathrm{NaF})$ is a highly consumed food additive, that is capable of disrupting the activities of several brain areas. It is unclear whether this compound affects the autonomic activities of the brain.

Objective: Therefore, this study was designed to investigate the ameliorative potentials of exogenous melatonin on sodium fluoride-induced pontine toxicity in adult male Wistar rats, as melatonin has been implicated to have a high concentration in the cerebrospinal fluid of injured brains.

Method: Thirty-two rats were randomly divided into 4 groups ( $\mathrm{n}=8$, per group). Groups I, II, III and IV received $0.2 \mathrm{ml}$ of normal saline (NS), $500 \mathrm{ppm}$ of sodium fluoride (NaF) via their drinking water, $10 \mathrm{mg} / \mathrm{kg}$ melatonin (MLT), and melatonin with sodium fluoride concurrently $(\mathrm{MLT}+\mathrm{NaF})$ respectively for fourteen days. At the end of these treatments, the rats were euthanized and brainstem tissues were excised for histological, histochemical, and biochemical analyses.

Results: There were shreds of evidence of DNA fragmentation, vacuolation, dispersion of the Nissl bodies, and axonal disruption in the cells of the basilar pons of the sodium fluoride-treated animals. This was coupled with high concentrations of malondialdehyde and low-level concentrations of glutathione reductase. Melatonin, however, was observed to limit neuronal injury in the cells of the basilar pons in the experimental animals by reducing the extent of cells undergoing process pyknosis, chromatolysis, and demyelination. Also, melatonin was able to reduce the concentration of malondialdehyde and increase glutathione reductase activities in the pons.

Conclusion: This study revealed that sodium fluoride injured the pontine histoarchitecture, and induced oxidative damage which were ameliorated by exogenous melatonin treatments.

Key words: Histoarchitecture, Melatonin, Oxidative damage, Pontine, Sodium fluoride, Wistar rats

Access this article online
Website: https:/www.nepjol.info/index.php/NJN
DOI: https://doi.org/10.3126/njn.v17i2.30110
HOW TO CITE
Ajoke SF, Ayodeji OA, Leken IA, Yetunde UR, Rukayat IA,
Aminu I, Yetunde AM, Monsur S, Raheem AAI, Iyabo AA, Salihu
AM. Exogenous Melatonin Ameliorates Pontine Histoarchitecture
and Associated Oxidative Damage in Sodium Fluoride Induced
Toxicity. NJNS. 2020;17(2):4-10

${ }^{1}$ ORCID iD: https://orcid.org/0000-0002-2955-7668 ${ }^{2}$ ORCID iD: https://orcid.org/0000-0003-4032-3712 ${ }^{3}$ ORCID iD: https://orcid.org/0000-0003-1060-1574 ${ }^{4}$ ORCID iD: https://orcid.org/0000-0002-0628-1507 ${ }^{5}$ ORCID iD: https://orcid.org/0000-0003-0865-372X ${ }^{6}$ ORCID iD: https://orcid.org/0000-0003-2371-3065 ${ }^{7}$ ORCID iD: https://orcid.org/0000-0001-8538-7838 ${ }^{8}$ ORCID iD: https://orcid.org/0000-0002-2955-7668 ${ }^{10}$ ORCID iD: https://orcid.org/0000-0001-9785-0033

\section{Introduction}

The effects of fluoride compounds on human health 1 are receiving global attention because of their widespread distribution and usage. ${ }^{1}$ Sodium fluoride

\author{
Address for correspondence: \\ Okesina Akeem Ayodeji \\ Department of Human Anatomy \\ Kampala International University \\ Western Campus, P.O Box 71 \\ Isha-ka/Bushenyi, Uganda \\ E-mail: akeemokesina@gmail.com \\ Contact number: $+256757847741,+2348033725777$ \\ Copyright (C) 2020 Nepalese Society of Neurosurgeons (NESON) \\ ISSN: 1813-1948 (Print), 1813-1956 (Online)
}

(i) (8) This work is licensed under a Creative Commons Attribution-Non Commercial 4.0 International License. 
tends to be beneficial to human health when consumed in minute quantity, ${ }^{2}$ as beers, soda, and juices. ${ }^{3}$ Also, it can serve as pesticide, rodenticides, fungicide for use on the farm, and a constituent of glass as an industrial product. ${ }^{4}$ Experimental animals have shown that chronic fluoride toxicity is said to affect the blood vessels and brain cells. Also, sodium fluoride has been implicated in increased production of free radicals, ${ }^{6,7}$ activation of the enzyme caspases, inhibition of glycolytic enzymes activities, ${ }^{7,8}$ and enhancement of inflammatory activities. ${ }^{9}$ Furthermore, sodium fluoride have been suggested to cause neural deficits in mammals, ${ }^{5}$ and this insult is independent of the route of administration when consumed in large amount. ${ }^{10}$ The long-term intake of fluoride has been established to lead to different motor deficits and mental illness. ${ }^{11}$

The pons forms part of the brain stem, a very organized structure that controls motor and sensory and autonomic activities. ${ }^{12}$ It is a complicated area of the brain, such that a small lesion can cause disastrous neurologic deficits, hence it is an important organ for survival. ${ }^{12}$ Also, the pontine nuclei located in the basilar part of the pons constitute the mossy fibers and forms the major pathway through which the cerebrum controls the activity of the cerebellum. ${ }^{12}$ The pontocerebellar fibers participate in some important functions, which include, vision, planning, initiation, and execution of movement. ${ }^{13}$

Melatonin is a hormone secreted by the pineal gland and plays an important role in sleep and wakefulness. ${ }^{14}$ Furthermore, melatonin has been implicated in several reports to have many therapeutic properties coupled with a neuroprotective role, which is evidenced by the ability to cross the blood-brain barrier. ${ }^{14,15}$ However, in humans, both the endogenous and exogenous melatonin acts as a good antioxidant in reducing oxidative stress. ${ }^{16}$ Patients with brain injury have high concentrations of endogenous CSF melatonin, which helps to reduce the level of oxidants in the pathogenesis of brain injury. ${ }^{16}$ Studies have suggested melatonin to work effectively against progressive fatal neurodegenerative disorders and neuropsychiatric conditions..$^{17,18}$

Existing literature have been associated with fluoride exposure to the cause of neurological motor and cognitive deficit in both matured and growing brains. ${ }^{19,20}$ Although, there has been lack of data to support the effect of fluoride on autonomic functions and possible therapeutic approaches. Therefore, the present study was initiated to evaluate the impact of sodium fluoride through drinking water on the activities of the pons. Additionally, melatonin was introduced to restore or stop the deleterious effects of sodium fluoride in the brains of these animals.

\author{
Methods
}

\section{Animal Design}

Forty-eight adult male Wistar rats (Rattus novergicus), weighing between 150-180 g were used for this study. The animals were obtained from the animal holdings of the Department of Zoology and were acclimatized in the animal house of the College of Health Sciences, University of Ilorin, for two weeks before the commencement of the various treatments. The animals were housed in cages under normal light/dark cycle, at normal room temperature/ humidity, and given adequate food and water ad libitum. ${ }^{21}$ This study was approved by the ethical review committee, faculty of basic medical sciences, University of Ilorin, Nigeria (UERC/ASN/2017/859).

The animals were randomly selected and grouped into 4 groups of 8 rats each i.e. $n=8$ per group. Groups I, II, III and IV received $0.2 \mathrm{ml}$ of normal saline (NS), $500 \mathrm{ppm}$ of sodium fluoride $(\mathrm{NaF})^{22}$ via their drinking water, $10 \mathrm{mg} /$ $\mathrm{kg}$ melatonin (MLT) ${ }^{23}$ and melatonin with sodium fluoride concurrently $(\mathrm{MLT}+\mathrm{NaF})$ respectively for fourteen days.

Note: the choice of 8 animals per group is to get a good statistically significant levels in case of mortality during the animal treatments.

\section{Tissue Collection}

All antibodies were procured from Dianova $(\mathrm{GmbH} /$ Warbugstr. 45/20354 Hamburg. Also, reagents and buffers used in this study were molecular biology grade (99.9\% pure) from Sigma-Aldrich. At the end of the various treatments i.e. Twenty-four hours later, the animals were sedated with intramuscular administration of $20 \mathrm{mg} / \mathrm{kg}$ of ketamine, ${ }^{24}$ perfused through the heart, and brainstem tissues were excised.

\section{Histological Analyses}

The tissues were fixed in 4 percent formaldehyde overnight before the pons was excised and further equilibrated in $30 \%$ sucrose solution. Sections were taken at $3 \mu \mathrm{m}$ on paraffin wax embedded tissue blocks and later mounted on a glass slide. Hematoxylin and eosin, Cresyl violet stain, and Luxol fast blue stain were used in this study. The tissue slides prepared from these stains, were observed under a light microscope and photographed using the Amscope eyepiece camera, followed by a qualitative comparison between control groups and the treated groups.

\section{Determination Biochemical Parameters}

The $0.1 \mathrm{~g}$ of the pons were homogenized $0.4 \mathrm{ml}$ of 5 percent sucrose solution and taken to the centrifuge. The homogenate was spun for 10 minutes at 5000 revolutions per minute and the supernatants were placed in plain 


\section{Ajoke et al}

bottles and taken for analysis. Oxidative stress parameters examined were malondialdehyde and glutathione peroxidase.

\section{Statistical Analyses}

This statistical test was performed using GraphPad Prism version 7.0. All data are expressed as the mean \pm standard error of the mean. Differences among the experimental groups were considered statistically significant when the p-value is $<0.05$ using one-way analysis of variance (ANOVA) and Tukey post-hoc test.

\section{Results}

\section{Sodium Fluoride Distorted the Histoarchitecture of Basilar Pons: Therapeutic Efficacy of Exogenous Melatonin}

The histological investigations were done on the basilar part of the pons and normal saline showed normal cytoarchitecture of the neurons with evidence of visible intact nuclei (Fig 1), normal appearance of Nissl bodies (Fig 2), blue and pink coloration indicating properly structured myelin fibers around the neuropil respectively (Fig 3). Sodium fluoride administration showed some condensed nuclei found in the neurons which indicates pyknosis, also seen are white patches of cells with empty cytoplasm which indicates vacuolation (Fig 1), dispersed Nissl bodies were seen which indicated chromatolysis (Fig 2 ), the concentration of highly disorganized blue coloration which indicated irregular patterns of myelin fibers found around the neuropil (Fig 3). Melatonin administration shows the majority of the neurons to be normal with their nuclei intact (Fig 1), normal arrangements of Nissl bodies, (Fig 2) and blue, and pink coloration indicative of normal appearance of myelin fibers found around the neuropil (Fig 3 ). The administration of melatonin with sodium fluoride revealed some intact neurons in the cytoplasm (Fig 1), regular patterns of Nissl bodies, (Fig 2) and the pattern blue and pink coloration indicated a better appearance and arrangement of the myelin fibers around the neuropil (Fig 3 ), even though sodium fluoride was also administered.

\section{Melatonin Action against Sodium Fluoride Induced Oxidative Damage}

The biochemical investigation revealed that the mean concentration of malondialdehyde in sodium fluoridetreated animals was significantly lower than that of the animals that received melatonin and melatonin with sodium fluoride (Fig 4), which indicated that melatonin reduces the production of malondialdehyde by limiting the peroxidation of polyunsaturated fatty acids in the pons produced from sodium fluoride actions. Furthermore, there was a significant increase in glutathione concentration in melatonin treated and melatonin with sodium fluoridetreated animals, when compared to sodium fluoride-treated animals (Fig 5), which revealed melatonin increases the activity of enzyme glutathione reductase in the pons and help to mop up free radicals produced within the cells of the animals (Fig 5), which revealed melatonin increases the activity of enzyme glutathione reductase in pons and help to mop up free radicals produced within the cells.

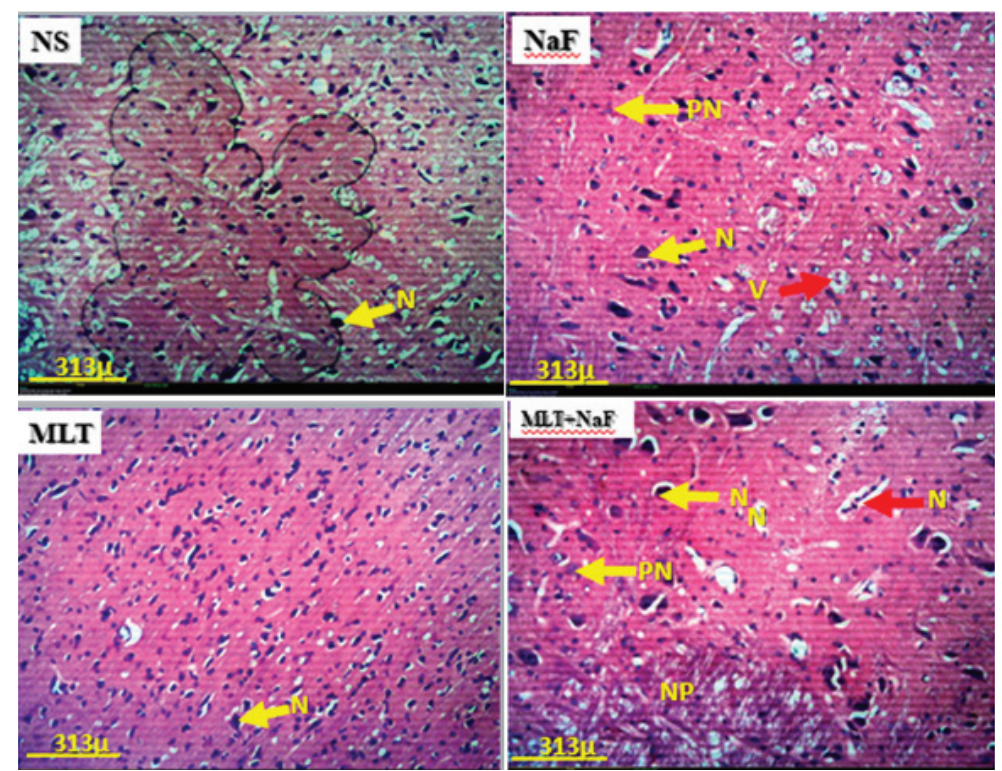

Figure 1: Haematoxylin and Eosin stains showing general cytoarchitecture of the basilar pons of rats, NS: multiple intact neurons with the presence of nuclei. NaF: evidence of pyknotic neurons (PN) and vacuolations (V). MLT: series of neurons with nuclei their nuclei present. MLT+NaF: few neurons showing evidence of pyknosis and vacuolation when compared to NaF. Scale bar $313 \mu$ 

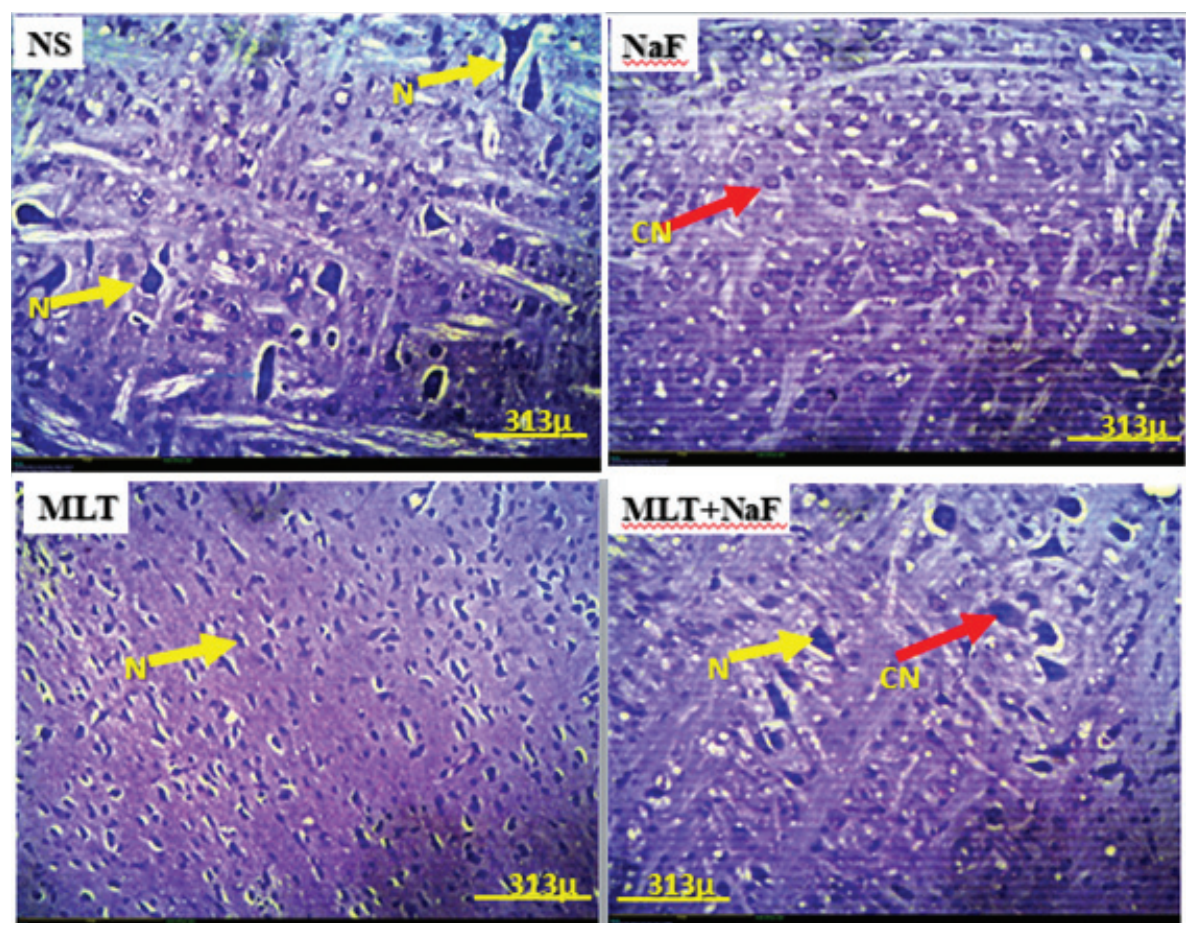

Figure 2: Cresyl fast violet stain showing the presence and arrangement of Nissl substance in the basilar pons of rats. NS: evidence of regular arrangement of the Nissl bodies in the neurons (N). NaF: dispersed and disintegration of Nissl bodies, evidence of chromatolysis as indicated by the chromatolytic neuron (CN). MLT: most of the Nissl bodies were well arranged within the cytoplasm. MLT+NaF: few cells undergoing chromatolysis as compared to NaF. Scale bar $313 \mu$

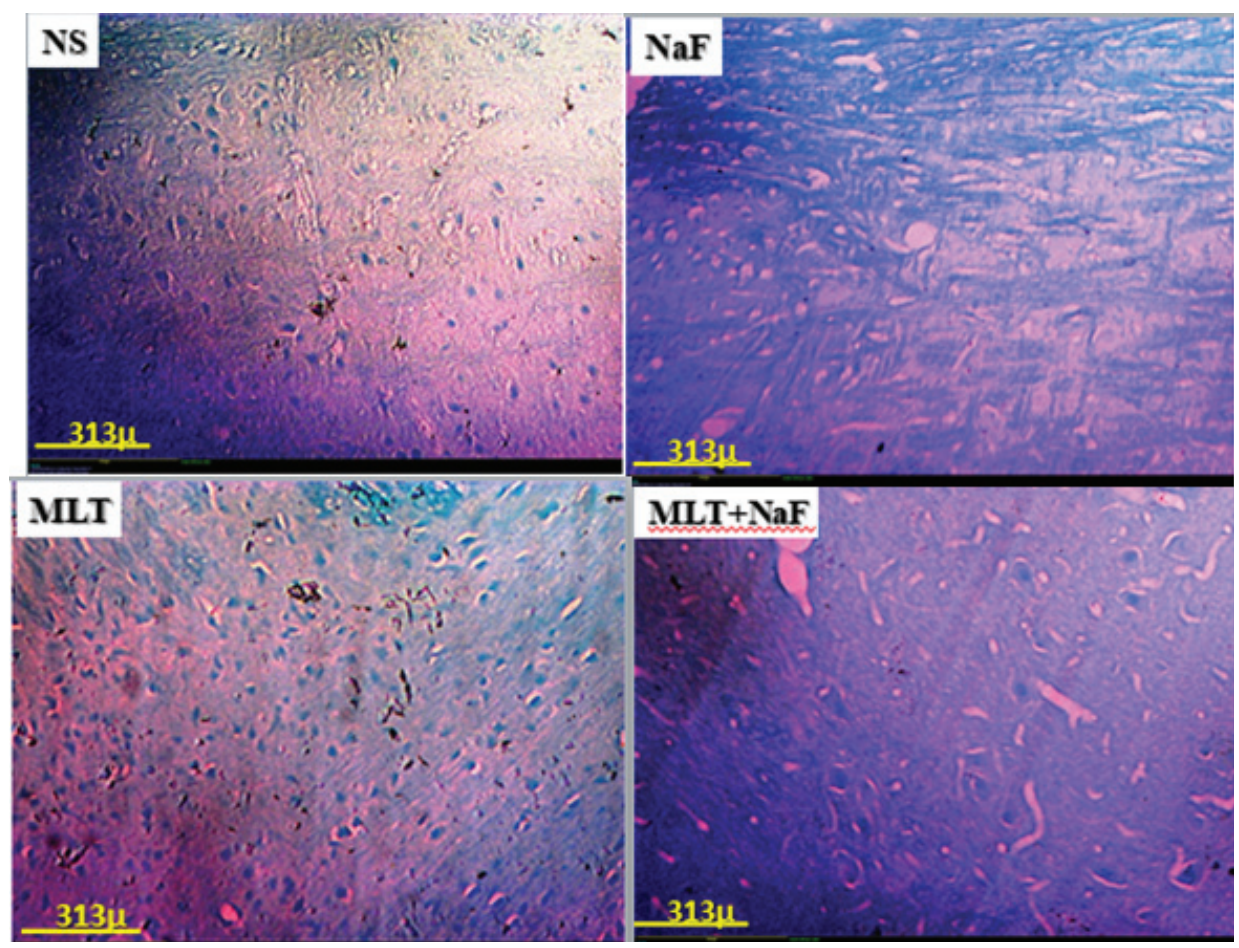

Figure 3: Luxol fast stain to demonstrate the arrangement of myelin fibers around the Neuropil in the basilar pons of rats. The blue and pink colors indicate myelin fibers and neuropil respectively. NS: myelin fibers appeared to be well arranged and structured found around the neuropil. NaF: evidence of abnormal appearance of the myelin fibers which indicted demyelination around the neuropil. MLT: majority of the myelin fibers appeared well organized around the neuropil. $M L T+N a F$ : myelin fibers appeared more structurally organized around the neuropil compared to NaF. Scale bar $313 \boldsymbol{\mu}$ 


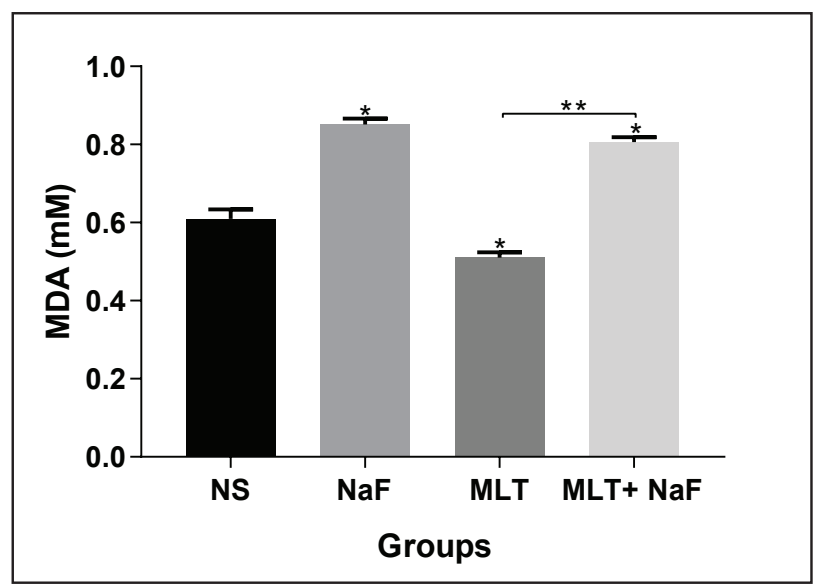

Figure 4: Malondialdehyde Concentration (MDA): NS: served as the positive control, NaF: served as the negative control, MLT: was significantly reduced when compared to $N a F, M L T+N a F$ : was significantly reduced as compared to NaF. * shows a statistically significant difference from $N S$, ** shows statistically significant difference from $\mathrm{NaF}$. $p<0.05$

\section{Discussion}

This study evaluated the ameliorative potentials of exogenous melatonin on sodium fluoride-induced toxicity on the pons of adult male Wistar rats.

The results indicated the detrimental effect of sodium fluoride as there was disruption in the pontine histoarchitecture of the sodium fluoride-treated rats, which showed various degrees of neural degeneration evidenced by the appearance of pyknotic cells, vacuolation, chromatolysis like changes. This is likely the case of DNA fragmentation causing extrusion of the nuclei contents out of the cells ${ }^{25}$ disruption in protein synthesis as a result of damage to the ribosomes, and rough endoplasmic reticulum which eventually led to dispersal and disintegration of the pontine cells. ${ }^{26,27}$ Also, the effect of sodium fluoride caused axonal degeneration which is evidenced by disruption in myelination of the neuropil and this constituted a slow conduction of action potentials of cells of the pons. ${ }^{28}$ The treatments with melanin showed reduced cellular vacuolation by limiting the extent of DNA fragmentation, nuclei extrusions, ${ }^{29-32}$ and helped reduce the process of chromatolysis by enhancing protein synthesis within the cells as evidenced by the majority of the cells were not undergoing disintegration and dispersion. ${ }^{33}$ Also, these melatonin treatments led to the restoration of axonal projections and myelination causing rapid conduction of action potentials among the cells of the basilar pons in these animals. ${ }^{34}$ This in line with the previous report that

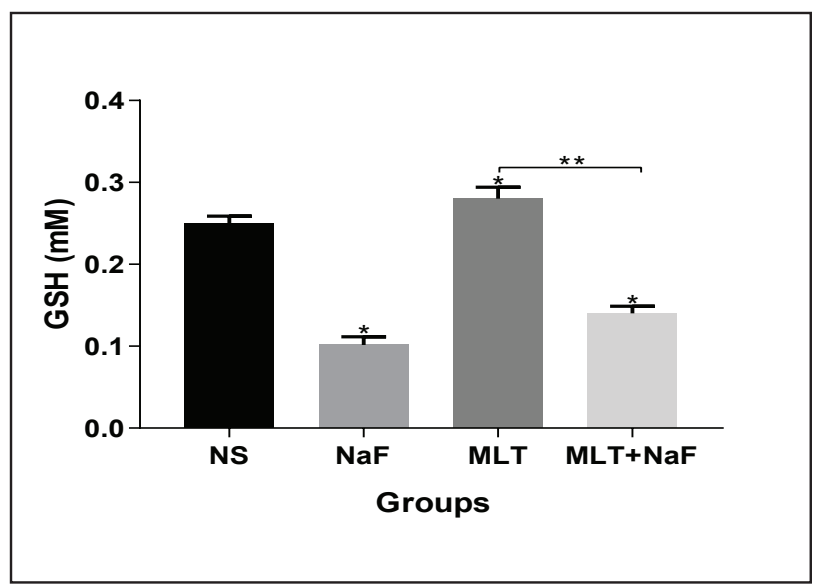

Figure 5: Glutathione Concentration (GSH): NS: served as the positive control, NaF: served as the negative control, MLT: was significantly increased when compared to NaF, $M L T+N a F$ : was significantly increased as compared to NaF. * shows a statistically significant difference from $N S$, ** shows statistically significant difference from $\mathrm{NaF}$. $p<0.05$

suggested pineal protein and melatonin can be useful in the control of neurotoxicity induced by fluoride ${ }^{35}$.

The normal physiological and biochemical activities of the brain, includes polyunsaturated fatty acids and energy requirements, makes it susceptible to free radicals mediated injury associated with sodium fluoride exposure. ${ }^{36}$ It was observed in this study that the pontine malondialdehyde concentration in the animals treated with Sodium fluoride was high, which indicates lipid peroxidation as a result of production polyunsaturated fatty acids, ${ }^{6,36,37}$ and glutathione levels were observed to be significantly lower in sodium fluoride-treated animals, which indicates sodium fluoride to inhibits the activity of antioxidant enzymes glutathione reductase. ${ }^{6,36}$ Furthermore, in this case, sodium fluoride led to the generation of reactive oxygen species, impaired mitochondria function, diminished cellular respiration, and promoted cytochrome $\mathrm{C}$ release in the cytosol which eventually causes the production of free radicals in the pons of the animals. ${ }^{37}$ The treatment with melatonin showed a reduction in Malondialdehyde concentrations in the pons of the animals. This statement suggests that melatonin treatments were able to reduce the concentration of reactive oxygen species and suppress the lipid peroxidation of polyunsaturated fatty acids in the pons of the animals. ${ }^{30,31,38,39}$ Also, the concentration of glutathione was observed to be reduced with melatonin treatment. This indicates that melatonin increased the activities of glutathione reductase, which in turn limited the circulation of free radicals in the pontine cells of the animals. ${ }^{15}$ 


\section{Conclusion}

The prolonged exposure to sodium fluoride caused cytoarchitectural and biochemical damages to the pons. However, exogenous melatonin served as a good therapeutic agent against sodium fluoride toxicity to the pons of adult Wistar rats.

Conflict of Interest: None

Source(s) of support: None

\section{References}

1. Kanduti D, Sterbenk P, Artnik. Fluoride: a Review of Use and Effects on Health. Mater Socio Medica. 2016;28(2):133. https://doi.org/10.5455/ msm.2016.28.133-137

2. Fordyce FM, Vrana K, Zhovinsky E, Povoroznuk V, Toth G, Hope BC, et al. A health risk assessment for fluoride in Central Europe. Environ Geochem Health. 2007;29(2):83-102. https://doi.org/10.1007/ s10653-006-9076-7

3. Thippeswamy HM, Kumar N, Anand SR, Prashant GM, Chandu GN. Fluoride content in bottled drinking waters, carbonated soft drinks and fruit juices in Davangere city, India. Indian J Dent Res. 2010;21(4):528-30. https://doi.org/10.4103/09709290.74206

4. Lund K, Refsnes M, Sandstrom T, Søstrand P, Schwarze P, Boe J, et al. Increased CD3 positive cells in bronchoalveolar lavage fluid after hydrogen fluoride inhalation. Scand J Work Environ Heal. 1999;25(4):326-34. https://doi.org/10.5271/ sjweh.442

5. Waugh DT. Fluoride exposure induces inhibition of sodium-and potassium-activated adenosine triphosphatase $(\mathrm{Na}+, \mathrm{k}+$-atpase) enzyme activity: Molecular mechanisms and implications for public health. Int J Environ Res Public Health. 2019;16(8):1427. https://doi.org/10.3390/ ijerph16081427

6. García-Montalvo EA, Reyes-Pérez H, Del Razo LM. Fluoride exposure impairs glucose tolerance via decreased insulin expression and oxidative stress. Toxicology. 2009;263(2-3):75-83.https://doi. org/10.1016/j.tox.2009.06.008

7. Mendoza-Schulz A, Solano-Agama C, ArreolaMendoza L, Reyes-Márquez B, Barbier O, Del Razo LM, et al. The effects of fluoride on cell migration, cell proliferation, and cell metabolism in $\mathrm{GH} 4 \mathrm{C} 1$ pituitary tumour cells. Toxicol Lett. 2009;190(2):179-86. https://doi.org/10.1016/j.toxlet.2009.07.014
8. Adamek E, Pawłowska-Góral K, Bober K. In vitro and in vivo effects of fluoride ions on enzyme activity. Annales Academiae Medicae Stetinensis. 2005; 51:69-85. PMID: 16519100

9. Lund K, Refsnes M, Ramis I, Dunster C, Boe J, Schwarze PE, et al. Human exposure to hydrogen fluoride induces acute neutrophilic, eicosanoid, and antioxidant changes in nasal lavage fluid. Inhal Toxicol. 2002;14(2):119-32. https://doi. org/10.1080/089583701753403944

10. Zhou Y, Qiu Y, He J, Chen X, Ding Y, Wang Y, et al. The toxicity mechanism of sodium fluoride on fertility in female rats. Food Chem Toxicol. 2013; 62:566-72. https://doi.org/10.1016/j.fct.2013.09.023

11. Shivarajashankara YM, Shivashankara AR. Neurotoxic Effects of Fluoride in Endemic Skeletal Fluorosis and in Experimental Chronic Fluoride Toxicity. J Clin Diagnostic Res. 2012;6(4):740-4.

12. Kiyatkin EA. Brain temperature homeostasis: Physiological fluctuations and pathological shifts. Front Biosci (Landmark Ed) 2010;15(1):73-92. https://doi.org/10.2741/3608

13. Sillitoe R V, Fu YH, Watson C. Cerebellum. In: The Mouse Nervous System. 2012. p. 360-97.

14. Naseem M, Parvez S. Role of melatonin in traumatic brain injury and spinal cord injury. Scientific World Journal. 2014. https://doi.org/10.1155/2014/586270

15. Hardeland R. Melatonin Metabolism in the Central Nervous System. Curr Neuropharmacol. 2010;8(3):168-81. https://doi. org/10.2174/157015910792246244

16. Ressmeyer AR, Mayo JC, Zelosko V, Sáinz RM, Tan DX, Poeggeler B, Antolín I, Zsizsik BK, Reiter RJ, Hardeland R. Antioxidant properties of the melatonin metabolite N1-acetyl-5-methoxykynuramine(AMK): Scavenging of free radicals and prevention of protein destruction. Redox Rep [Internet]. 2003;8(4):20513. https://dx.doi.org/10.1179/135100003225002709

17. Reiter JR, Tan DX, Qi W, Manchester LC, Karbownik M, Calvo JR. Pharmacology and physiology of melatonin in the reduction of oxidative stress in vivo. Biol Signals Recept. 2000;9(3-4):160-71. https:// doi.org/10.1159/000014636

18. Reiter RJ, Tan DX, Mayo JC, Sainz RM, Leon J, Czarnocki Z. Melatonin as an antioxidant: Biochemical mechanisms and pathophysiological implications in humans. Acta Biochimica Polonica. 2003; 50:1129-46. PMID: 14740000

19. Kinawy AA. The potential roles of aluminum chloride and sodium fluoride on the neurotoxicity of the cerebral cortex, hippocampus, and hypothalamus of male rat offspring. J Basic Appl Zool. 2019;80(17). https://doi.org/10.1186/s41936-019-0086-2 
20. Paul V, Ekambaram P, Jayakumar AR. Effects of sodium fluoride on locomotor behavior and a few biochemical parameters in rats. Environ Toxicol Pharmacol. 1998;6(3):187-91. https://doi. org/10.1016/s1382-6689(98)00033-7

21. Institute for Laboratory Animal Research. Animal care and use program. In: Guide for the Care and Use of Laboratory Animals [Internet]. 2011. p. 11-40. Available from: https://www.stcloudstate. edu/iacuc/_files/documents/animal-care-and-useprogram.pdf

22. Kour K, Singh J. Histological finding of mice testes following fluoride ingestion. Fluoride - Q Reports. 1980;13(4):160-2.

23. Bustos-Obregón E, Poblete D, Catriao R, Fernandes FH. Protective Role of Melatonin in Mouse Spermatogenesis Induced by Sodium Arsenite. Int J Morphol. 2013;31(3):849-56. Available from: http:// www.intjmorphol.com/wp-content/uploads/2016/09/ Art_12_3132013.pdf

24. Zanos P, Moaddel R, Morris PJ, Riggs LM, Highland $\mathrm{JN}$, Georgiou $\mathrm{P}$, et al. Ketamine and ketamine metabolite pharmacology: Insights into therapeutic mechanisms. Pharmacol Rev. 2018;70(3):621-60. https://doi.org/10.1124/pr.117.015198

25. Wang M, Xing HJ, Zhu F, Xu SW. Effect of fluoride on apoptosis and DNA damage in ox peripheral blood lymhocytes. Chinese J Endem. 2008;27(3):272-5.

26. Sharma R, Tsuchiya M, Bartlett JD. Fluoride induces endoplasmic reticulum stress and inhibits protein synthesis and secretion. Environ Health Perspect. 2008;116(9):1142-6. https://doi.org/10.1289/ ehp. 11375

27. Chinoy NJ, Mehta D, Jhala DD. Effects of different protein diets on fluoride induced oxidative stress in mice testis. Fluoride. 2005;38(4):269-75. https:// www.fluorideresearch.org/391/files/39111-16.pdf

28. Woods IG, Lyons DA, Voas MG, Pogoda HM, Talbot WS. nsf Is Essential for Organization of Myelinated Axons in Zebrafish. Curr Biol. 2006;16(7):636-48. https://doi.org/10.1016/j.cub.2006.02.067

29. Webb SM, Puig-Domingo M. Role of melatonin in health and disease. Clinical Endocrinology. 1995;42: 221-34. https://doi.org/10.1111/j.1365-2265.1995. tb01869.x.

30. Aldhous M, Franey C, Wright J, Arendt J. Plasma concentrations of melatonin in man following oral absorption of different preparations. Br $\mathbf{J}$
Clin Pharmacol. 1985;19(4):517-21. https://doi. org/10.1111/j.1365-2125.1985.tb02679.x

31. Chetsawang J, Govitrapong P, Chetsawang B. Melatonin inhibits MPP-induced caspase-mediated death pathway and DNA fragmentation factor-45 cleavage in SK-N-SH cultured cells. J Pineal Res. 2007;43(2):115-20. https://doi.org/10.1111/j.1600079X.2007.00449.x

32. Akbulut KG, Akbulut $\mathrm{H}$, Akgun N. Melatonin decreases DNA fragmentation and oxidative stress parameters of gastrointestinal mucosa. Drug Metab Rev. 2010;42(supp1):99-100.

33. Sokolovic D, Djordjevic B, Kocic G, Stoimenov TJ, Stanojkovic Z, Sokolovic DM, et al. The effects of melatonin on oxidative stress parameters and DNA fragmentation in testicular tissue of rats exposed to microwave radiation. Adv Clin Exp Med. 2015;24(3):429-36. https://doi.org/10.17219/ acem $/ 43888$

34. Zhao XM, Hao HS, Du WH, Zhao SJ, Wang HY, Wang $\mathrm{N}$, et al. Melatonin inhibits apoptosis and improves the developmental potential of vitrified bovine oocytes. J Pineal Res. 2016;60(2):132-41. https://doi.org/10.1111/jpi.12290

35. Bharti VK, Srivastava RS. Fluoride-induced oxidative stress in rat's brain and its amelioration by buffalo (bubalus bubalis) pineal proteins and melatonin. Biol Trace Elem Res. 2009;130(2):131-40. https://doi. org/10.1007/s12011-009-8320-2

36. Hassan HA, Yousef MI. Mitigating effects of antioxidant properties of black berry juice on sodium fluoride induced hepatotoxicity and oxidative stress in rats. Food Chem Toxicol. 2009;47(9):2332-7.

37. Zhang M, Wang A, He W, He P, Xu B, Xia T, et al. Effects of fluoride on the expression of NCAM, oxidative stress, and apoptosis in primary cultured hippocampal neurons. Toxicology. 2007;236(3):20816. https://doi.org/10.1016/j.tox.2007.04.007

38. Acuña-Castroviejo D, Martín M, Macías M, Escames G, León J, Khaldy H, et al. Melatonin, mitochondria, and cellular bioenergetics. Journal of Pineal Research. 2001;30:65-74. https://doi.org/10.1034/ j.1600-079x.2001.300201.x

39. Bonnefont-Rousselot D, Collin F. Melatonin: Action as antioxidant and potential applications in human disease and aging. Toxicology. 2010;278(1):55-67. https://doi.org/10.1016/j.tox.2010.04.008. 